\title{
Developmental and Nutritional Determinants of Pregnancy Outcome Among Teenagers
}

\author{
A. ROBERTO FRISANCHO, JORGE MATOS, WILLIAM R. LEONARD, \\ AND LUCIA ALLEN YAROCH \\ Center for Human Growth and Development and Department of \\ Anthropology, University of Michigan, Ann Arbor, Michigan 48109 (A.R.F., \\ W.R.L., L.A.Y.), and Servicio Asociados de Pediatria, Avenida Bartolome \\ Herrera 238, Lima, Peru (J.M.)
}

\begin{abstract}
KEY WORDS Peru, Nutrition, Growth, Teenage pregnancy, Birth weight, Placenta size
\end{abstract}

\begin{abstract}
To investigate the determinants of low birth weight in infants born to adolescent mothers, we studied the obstetric population attended at the Maternity Hospital of Lima, Peru. From this population, 1256 gravidas, ranging in age from 12 to 25 years, volunteered to participate in this study. Anthropometric and biochemical measurements were used to evaluate the nutritional status and physiological maturity of the mother and newborn. For analytical reasons the young teenaged mothers (less than 15 years) were classified as either still-growing or having completed their growth, depending on their height relative to their parents' height. Similarly, the young teenagers were classified as either gynecologically immature or gynecologically mature depending on whether their gynecological age was less than or greater than 2 years.

Our results indicate that young still-growing teenagers, even when matched for nutritional status, have smaller newborns than adult mothers. The data also demonstrate that maternal gynecological age per se does not affect prenatal growth. As inferred from multivariate analyses, it appears that the reduction in birth weight among young teenagers can be explained in part by a decreased net availability of nutrients resulting from the competition for nutrients between the mother's growth needs and the growth needs of her fetus and by an inability of the teenage placenta to maintain placental function adequately for active fetal growth.
\end{abstract}

Early studies have shown that mothers less than 16 years old are at a greater risk of having preterm deliveries, low birth weight infants, stillbirths, and neonatal deaths than adult mothers (Briggs et al., 1962; Battaglia et al., 1963; Israel and Wouterz, 1963; Stearn, 1963; Claman and Bell, 1964; Hulka and Schaaf, 1964; Coates, 1970; Coetzee, 1970; Clark, 1971; Niswander and Gordon, 1972; Raugh et al., 1973; Duenhoelter et al., 1975; Zlatnik and Burmeister, 1977). From an analysis of more than 3 million births that occurred in 1976 in the U.S., it is evident that irrespective of race, parity, prenatal care, mother's educational level, or marital status, teenagers have a greater percentage of low birth weight infants than do adults (Taffell, 1980). Many hypotheses have been postulated to explain the poor pregnancy outcomes of teenagers. Some have attributed it to physiological immaturity (Erkan et al., 1971; Zlatnik and Burmeister, 1977), while others have suggested that it is due to a competition for nutrients between the growing teenager and her fetus (Naeye, 1981a). However, at present the influence of these factors on pregnancy outcome of teenagers is not well defined. In an attempt to determine the developmental and nutritional determinants of pregnancy outcome among teenag-

\footnotetext{
Received November 23, 1983; accepted April 26, 1984.
} 
ers, in 1980 we initiated a prospective and cross-sectional study of pregnant adolescents and their newborns in a Peruvian urban population. In previous publications we have reported on the interaction between pregnancy weight gain and prenatal growth of infants born to adolescent and adult mothers (Frisancho et al., 1983), adolescent maturity and birth weight (Frisancho et al., 1984b), and the role of adolescent growth status, placenta function, and birth weight (Frisancho et al., 1984a). Hence, the purpose of this article is to integrate these studies as well as to present additional information about the developmental and nutritional determinants of prenatal growth retardation associated with teenage pregnancy.

\section{MATERIALS AND METHODS}

\section{Sample}

In 1980 we initiated a prospective and cross-sectional study of teenage mothers and their newborns attended at the Maternity Hospital of Lima, Peru. Each year, an average of 35,000 women are attended for delivery at this hospital. From this population we studied a sample of 1256 gravidas ranging in age at conception from 12 to 25 years who volunteered to participate in this study. All of these participants were studied cross-sectionally at the time of delivery, but 440 women were studied twice: once at the first trimester of pregnancy and again at the day of delivery. In addition, 650 parents of the pregnant teenagers were included for detailed anthropometric evaluation.

Socioeconomic characteristics: The socioeconomic information included place of birth, length of residence at present place of residence, years of schooling, family housing (location, type of housing, number of rooms, furniture in house, etc.), occupation of subjects and of parents, and sanitary habits. Frequency of smoking and drug use was obtained from each participating subject.

As shown in Table 1, two-thirds of the gravidas were either single or living in commonlaw union and the remainder were married; about $46 \%$ of the sample had no elementary education and $36 \%$ had between 1 and 5 years of schooling. About half of the gravidas were maids and the rest were unemployed. Less than $3 \%$ of the sample smoked, and a similar percentage drank alcohol. Less than $1 \%$ chewed coca leaves. All these cases were excluded from the present study. About $95 \%$ of the adolescent gravidas were primiparous, and for the present study only these primiparous nonsmoking subjects were included.

Medical examination: All participants, when admitted to the Maternity Hospital, were given a standard medical examination to determine their health status. All the information was recorded in the obstetric prenatal record specially designed for this study. This examination included information about previous obstetric history, past medical history, age at menarche, age at first intercourse, and a physical and pelvic examination. At this visit the medical staff also obtained information regarding height of the fundus, weight, blood pressure, position of the fetus, fetal heart rate, and any evidence of maternal edema.

Biochemical: The examination included analysis of hemoglobin, hematocrit, serum protein, serum albumin, serum iron, total iron binding capacity, and percent transferrin saturation $(\% \mathrm{TS}=$ serum iron $/ \mathrm{TIBC} \times$ 100).

Anthropometry: Maternal anthropometric dimensions measured included height $(\mathrm{cm})$, weight $(\mathrm{kg})$, skinfold thickness $(\mathrm{mm})$ at the triceps, subscapula, midaxilla, and calf, and circumference $(\mathrm{cm})$ at the upper arm, calf, and waist. Estimates of upper arm and calf muscle area $\left(\mathrm{mm}^{2}\right)$ were derived following procedures described previously (Frisancho et al., 1977a,b; Frisancho, 1981). We also obtained information on prepregnancy weight and pregnancy weight gain. For this purpose two procedures were employed. First, all subjects were asked about their weight before pregnancy. Second, the weight of all subjects admitted was measured at delivery, and prepregnancy weight was estimated retrospectively using the expected weight-for-height tables of adult Latin American women during pregnancy (Gueri et al., 1982). These reference standards assume an increase of $1.7 \%$ in weight during the first 13 weeks of pregnancy and a gain of $18.3 \%$ spread uniformly over the remaining 27 weeks (i.e., $0.678 \%$ per week). Therefore, weight at delivery can be used to estimate prepregnancy weight. Comparison of the two estimates of pregnancy gave almost identical values. For this reason, for each individual on whom we had information on both reported prepregnancy weight and weight at delivery, we derived a new average prepregnancy weight that incorporated both estimates. Hence, the prepregnancy weight and corresponding weight 
TABLE 1. Socioeconomic and demographic characteristics of 1020 adolescent mothers aged 12 to 16 years studied at the Maternity Hospital of Lima, Peru

\begin{tabular}{|c|c|c|c|}
\hline Characteristic & Percent & Characteristic & Percent \\
\hline $\begin{array}{l}\text { Civil status } \\
\text { Single } \\
\text { Married } \\
\text { Lives with boyfriend }\end{array}$ & $\begin{array}{l}18 \\
35 \\
47\end{array}$ & $\begin{array}{l}\text { Drinks alcohol } \\
\text { No } \\
\text { Yes }\end{array}$ & $\begin{array}{r}97 \\
3\end{array}$ \\
\hline $\begin{array}{l}\text { Years of schooling } \\
\text { None } \\
\text { One to five } \\
\text { Six to ten } \\
\text { Eleven to twenty }\end{array}$ & $\begin{array}{r}46 \\
36 \\
18 \\
0\end{array}$ & $\begin{array}{l}\text { Living arrangements } \\
\text { With spouse or boyfriend } \\
\text { With spouse and parents } \\
\text { With spouse and in-laws } \\
\text { With others or at work place }\end{array}$ & $\begin{array}{l}30 \\
45 \\
15 \\
10\end{array}$ \\
\hline $\begin{array}{l}\text { Occupation } \\
\text { Maid } \\
\text { Not working } \\
\text { Other }\end{array}$ & $\begin{array}{r}59 \\
40 \\
1\end{array}$ & $\begin{array}{l}\text { Type of housing } \\
\text { Public housing } \\
\text { Slum } \\
\text { Other }\end{array}$ & $\begin{array}{r}46 \\
49 \\
5\end{array}$ \\
\hline $\begin{array}{l}\text { Smokes } \\
\text { No } \\
\text { Yes }\end{array}$ & $\begin{array}{r}97 \\
3\end{array}$ & $\begin{array}{l}\text { Previous pregnancies } \\
\text { None } \\
\text { One or more }\end{array}$ & $\begin{array}{r}95 \\
5\end{array}$ \\
\hline $\begin{array}{l}\text { Chews coca } \\
\text { No } \\
\text { Yes }\end{array}$ & $\begin{array}{r}99 \\
1\end{array}$ & $\begin{array}{l}\text { Previous abortions or stillbirths } \\
\text { (Among the } 5 \% \text { previously pregnant) } \\
\text { None } \\
\text { One or more }\end{array}$ & $\begin{array}{r}96 \\
4 \\
\end{array}$ \\
\hline
\end{tabular}

gain used here are based upon these corrected values. In addition, measurement of postpartum weight (taken betweeen 12 and 24 hours after delivery) was obtained. Based on this information, the conceptus weight was obtained by subtracting the postpartum from the prepartum weight.

Newborns: All newborns were examined by a neonatologist and the medical staff. This examination included standard evaluations for Apgar scores at 1 and 5 minutes and Dubowitz scores following the protocol of Ballard et al. (1979). Scores for physical and neuromuscular maturity of newborns were separately recorded. The total Dubowitz scores were then extrapolated to the corresponding gestational age, hereafter referred to as maturation gestational age. As complementary information, gestational age was also derived from information about date of last menstrual period of the mother, hereafter referred to as menstruation-based gestational age. Within 6 hours of birth, all newborns were weighed (gm) and measured for length $(\mathrm{cm})$, for skinfold thickness (mm) at the triceps, subscapula, and midaxilla, and for circumference $(\mathrm{cm})$ at the head, chest, upper arm, and calf. The skinfolds at triceps, subscapula, and midaxilla were summed. These measurements were taken by a pediatrician and nurses properly trained by the authors (A.R.F., J.M.). Following the procedures of our previous studies (Frisancho et al., 1977b), a randomly selected subsample of $10 \%$ of all adolescent mothers and their newborns were re-measured for accuracy.

Placenta measurements: Immediately after delivery the placenta was weighed with all the fluid. Thereafter the placenta was suspended for 1 hour, allowing the fluid to drain away, after which the placenta was weighed again. The humid and fluid-drained placenta weights were recorded as part of the neonatal record.

\section{RESULTS}

\section{Age trends}

Evaluation of the data indicated that for mothers aged 17 years and older, the newborn characteristics were similar to those of infants born to adult women. For this reason, the data for infants born to mothers between 12 and 16 years were analyzed by 1 -year intervals, and those born to mothers older than 17 years were grouped together. Table 2 summarizes the maternal and newborn biological characteristics by age at pregnancy. These data show increasing mean values of age at menarche, prepregnancy weight, and weight at delivery from the 12th to 16th year, along with a slight increase in height. Similarly, 
newborn weight increases systematically with increasing maternal age from the $12 \mathrm{th}$ to 16 th year. Neither the maternal nor the newborn measurements show any age-associated differences after a maternal age of 17 years. The increase in birth weight between 12 and 17 years averages about $200 \mathrm{gm}$. In contrast to these changes, there are no major age-associated differences in average pregnancy weight gain or in gestation lengths derived either from maturity scores or from dates of last menstruation. Similarly, there were no age-associated differences in biochemical measurements such as hemoglobin, hematocrit, or serum values of protein, albumin, iron, or percent transferrin (not shown here).

Because both maternal body size and newborn weight increase with maternal age in young adolescents, it is not clear to what extent the reduction in birth weight is due either to the smaller maternal body mass before and during pregnancy or to differences in age at pregnancy. Therefore, in order to test for statistical differences between birth weights at each maternal age, several analyses of covariance were performed in an effort to control for differences in maternal body size before pregnancy and at delivery. This approach enabled us to control for the influence of body size while allowing chronological age to vary. Table 3 presents a summary of the results of these analyses of covariance. From these data it is evident that newborn weight increases with age even when height, weight, sum of skinfolds, and muscle area are adjusted for; i.e., the birth weight of offspring born to mothers under the age of 16 years continues to be significantly lower than the birth weight of those born to their 17- to 25-year-old counterparts. That is, young teenage mothers, even if they had the same height and weight and same amount of fatness and muscularity at delivery as their older counterparts, would have smaller newborns.

Table 4 shows birth weight adjusted for pregnancy weight gain. It is evident that after correcting for differences in pregnancy weight gain, teenage mothers aged 13 to 15 years had smaller newborns than their 16- to 25-year-old counterparts. The difference in newborn weight between 13-14 and 17-25 year olds is statistically significant.

Figure 1 illustrates the relationship between prepregnancy weight and newborn weight of infants born to 13- to 15-, 16-, and
17- to 25-year-old mothers. This graph shows that for young teenage mothers and those older than 17 years, the birth weights associated with a particular prepregnancy weight are quite similar. In contrast, and as illustrated in Figure 2, the birth weights of infants born to young teenage mothers (13 to 15 years) are significantly lower than those born to older teenage mothers who have the same pregnancy weight gain. This figure also shows that the pregnancy weight gain associated with the average birth weight of 3220 gm equals about $16 \mathrm{~kg}$ for the 13- to 15-yearolds, about $11.5 \mathrm{~kg}$ for the 16-year-olds, and about $10 \mathrm{~kg}$ for those 17 years old and older. It must be noted that the differences in the relationship between weight gain and birth weight within each maternal age group were statistically significant at the 0.05 level or better.

\section{Maternal anthropometric status}

Another way of separating the influence of nutritional status and maternal age on prenatal growth is to compare the birth weight of infants born to mothers of the same nutritional status but of different ages. With this purpose, we have classified the teenage mothers into two categories of nutritional status, good and poor. The subjects were classified as being of either good or poor nutritional status according to whether their prepregnancy weight, pregnancy weight gain, height, weight, sum of skinfolds, or upper arm muscle area at delivery were greater or less than the age-specific mean values for these respective measurements. Table 5 compares the birth weight and sum of skinfolds of infants born to young adolescent mothers and older women of good nutritional status. These data show that the young teenage mothers had newborns who on the average weighed 97 to $142 \mathrm{gm}$ less than those born to older women of similar nutritional status. Furthermore, the young teenage mothers had newborns who also had significantly thinner skinfolds than the infants born to older women.

\section{Gynecological maturity}

From the original sample, 412 primiparous adolescents were selected in order to study the role of gynecological maturity in prenatal growth. The criterion for inclusion in this part of the study was that chronological age at conception be less than 15 years. Based on the information of age at menarche and 

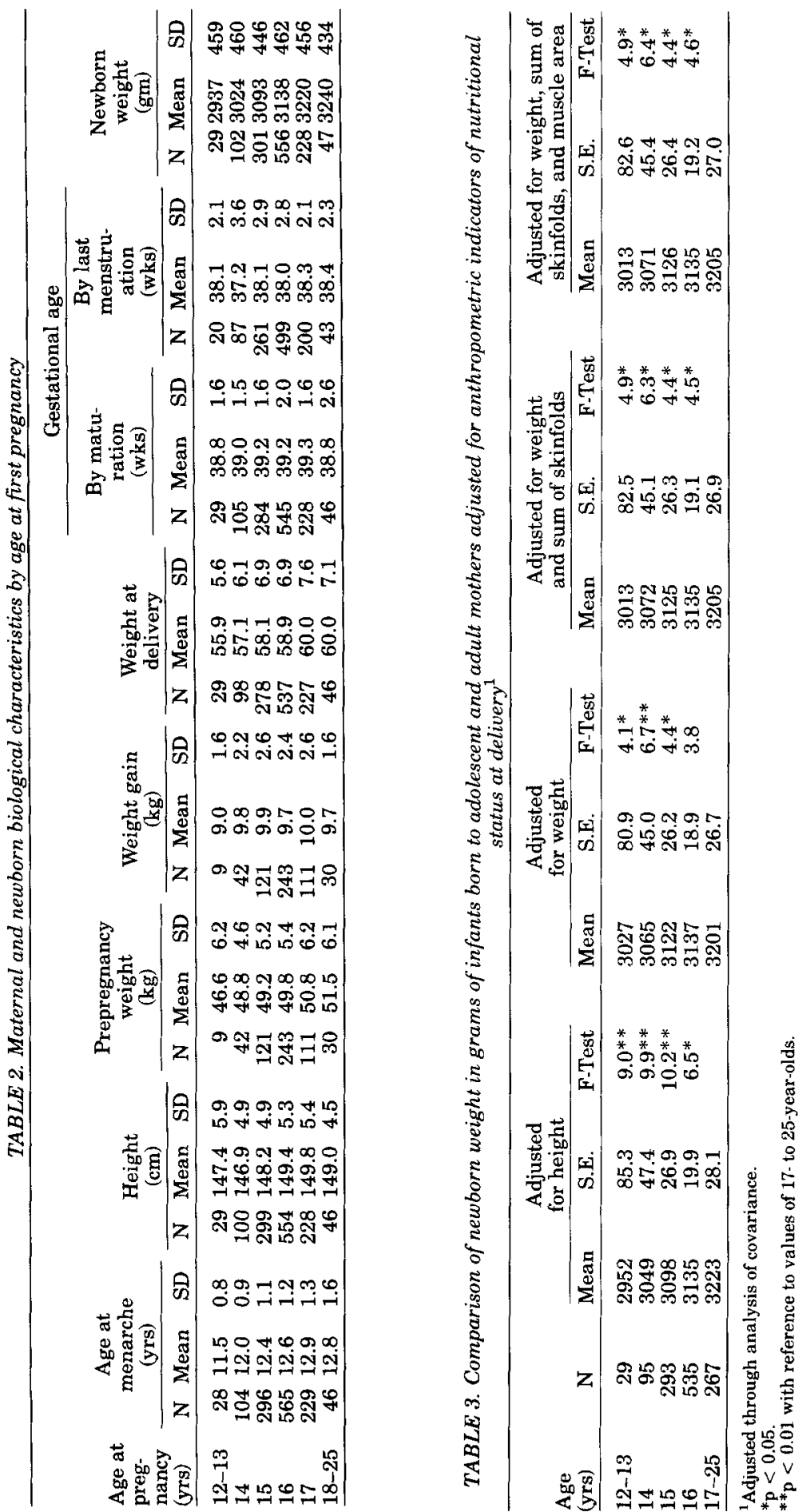
TABLE 4. Comparison of newborn weight in grams of infants born to adolescent and adult mothers, adjusted for pregnancy weight gain ${ }^{1}$

\section{Newborn weight}

adjusted for pregnancy weight

\begin{tabular}{lrccc}
$\begin{array}{l}\text { Age } \\
\text { (yrs) }\end{array}$ & $\mathrm{N}$ & Mean & S.E. & F-Test \\
\hline $13-14$ & 50 & 3007 & 60.6 & $9.21^{*}$ \\
15 & 121 & 3122 & 38.9 & 3.46 \\
16 & 238 & 3147 & 27.8 & 2.63 \\
$17-25$ & 137 & 3222 & 36.6 & \\
\hline
\end{tabular}

'Adjusted through analysis of covariance.

${ }^{*} p<0.01$ with reference to values of 17 - to 25 -year-olds.

age at conception, the gynecological age was calculated (gynecological age $=$ age at conception - age at menarche). On the basis of this information, the adolescents were classified as either low gynecological age or high gynecological age, depending on whether their gynecological age was less than or greater than 2 years.

In Table 6 the birth weight, placenta weight, maturity scores, and gestational ages of the newborns are compared according to their mothers' gynecological age; these variables are adjusted for anthropometric indicators of maternal nutritional status. From this it is evident that there are no differences in birth weight or placenta weight that can be associated with gynecological age differences. Similarly, the maturity scores and gestational ages of the infants born to mothers with low gynecological age are indistinguishable from those of infants born to high gynecological age mothers. These findings do not support the hypothesis that gynecological age per se is an important risk factor affecting prenatal growth and maturity of infants born to adolescent mothers.

\section{Growth status}

In an attempt to understand the role of the adolescent's relative growth status on prenatal growth, we selected those teenagers whose age at conception was less than 15 years and whose parents' anthropometric measurements were obtained at the time the adolescent was attended for delivery. There were a total of 424 teenagers in this age group for whom we obtained only the mother's height and 226 teenagers for whom we obtained information on both mother's and father's height. Fifty-nine percent of the teenagers had a height greater than or equal to their mothers' height. On the other hand, with the exception of six teenagers, none

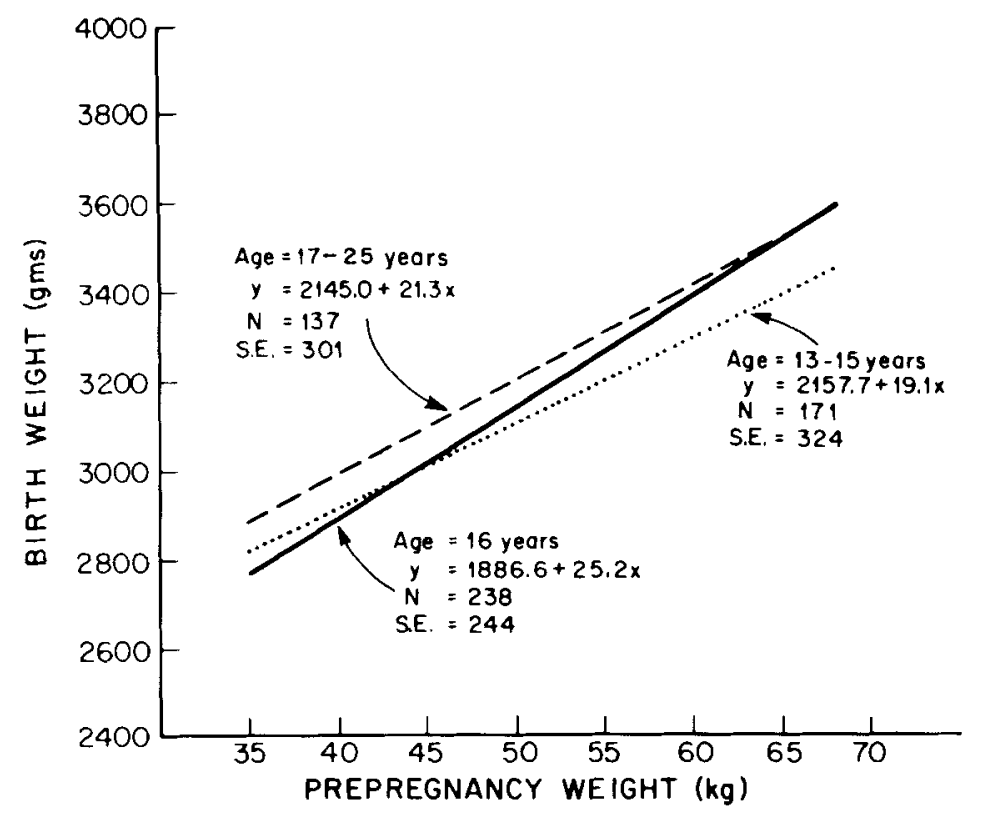

Fig. 1. Relationship of prepregnancy weight and newborn weight of infants born to young teenage mothers and older women. Note that at the same prepregnancy weight, maternal age is not related to newborn weight. 
TABLE 5. Comparison of newborn weight and sum of skinfolds of offspring of young (13 to 16 years) and older (17 to 25 years) mothers with good nutritional status ${ }^{1}$

\begin{tabular}{|c|c|c|c|c|c|c|}
\hline \multirow{2}{*}{$\begin{array}{l}\text { Age at } \\
\text { conception } \\
\text { (yrs) }\end{array}$} & \multicolumn{3}{|c|}{ Birth weight (gm) } & \multicolumn{3}{|c|}{ Sum of skinfolds (mm) } \\
\hline & $\mathbf{N}$ & Mean & S.D. & $\mathbf{N}$ & Mean & S.D. \\
\hline \multicolumn{7}{|c|}{ By prepregnancy weight } \\
\hline $13-16$ & 224 & 3198.2 & 408 & 215 & 12.4 & 2.9 \\
\hline $17-25$ & 82 & 3295.5 & 425 & 78 & 13.4 & 3.8 \\
\hline F-Test & & 3.05 & N.S. & & 5.64 & $\mathrm{p}<.02$ \\
\hline \multicolumn{7}{|c|}{ By pregnancy weight gain } \\
\hline $13-16$ & 185 & 3200.6 & 415 & 182 & 12.3 & 2.8 \\
\hline $17-25$ & 74 & 3339.1 & 452 & 69 & 13.5 & 3.9 \\
\hline F.Test & & 5.44 & $p<0.02$ & & 8.22 & $\mathrm{p}<0.005$ \\
\hline \multicolumn{7}{|c|}{ By height at delivery } \\
\hline $13-16$ & 573 & 3128.8 & 482 & 554 & 11.9 & 2.9 \\
\hline $17-25$ & 170 & 3268.5 & 463 & 167 & 12.9 & 3.6 \\
\hline F-Test & & 11.99 & $\mathrm{p}<0.0006$ & & 15.64 & $p<0.0001$ \\
\hline \multicolumn{7}{|c|}{ By weight at delivery } \\
\hline $13-16$ & 448 & 3220.1 & 442 & 439 & 12.3 & 3.0 \\
\hline $17-25$ & 134 & 3326.2 & 440 & 131 & 13.4 & 3.7 \\
\hline F-Test & & 5.84 & $\mathrm{p}<0.02$ & & 11.91 & $\mathrm{p}<0.0006$ \\
\hline \multicolumn{7}{|c|}{ By sum of skinfolds at delivery } \\
\hline $13-16$ & 443 & 3155.0 & 461 & 432 & 12.3 & 3.0 \\
\hline $17-25$ & 123 & 3288.0 & 417 & 122 & 13.1 & 3.1 \\
\hline F-Test & & 8.08 & $p<0.005$ & & 6.64 & $\mathrm{p}<0.01$ \\
\hline \multicolumn{7}{|c|}{ By upper arm muscle area at delivery } \\
\hline $13-16$ & 459 & 3152.9 & 459 & 449 & 11.6 & 2.8 \\
\hline $17-25$ & 118 & 3294.4 & 429 & 116 & 12.5 & 3.4 \\
\hline F.Test & & 8.91 & $\mathrm{p}<0.003$ & & 7.53 & $p<0.007$ \\
\hline
\end{tabular}

${ }^{1}$ Mothers with good nutritional status are defined as those above the age-specific mean value of prepregnancy weight, pregnancy weight gain, height at delivery, weight at delivery, sum of skinfolds at delivery, or upper-arm muscle area at delivery.

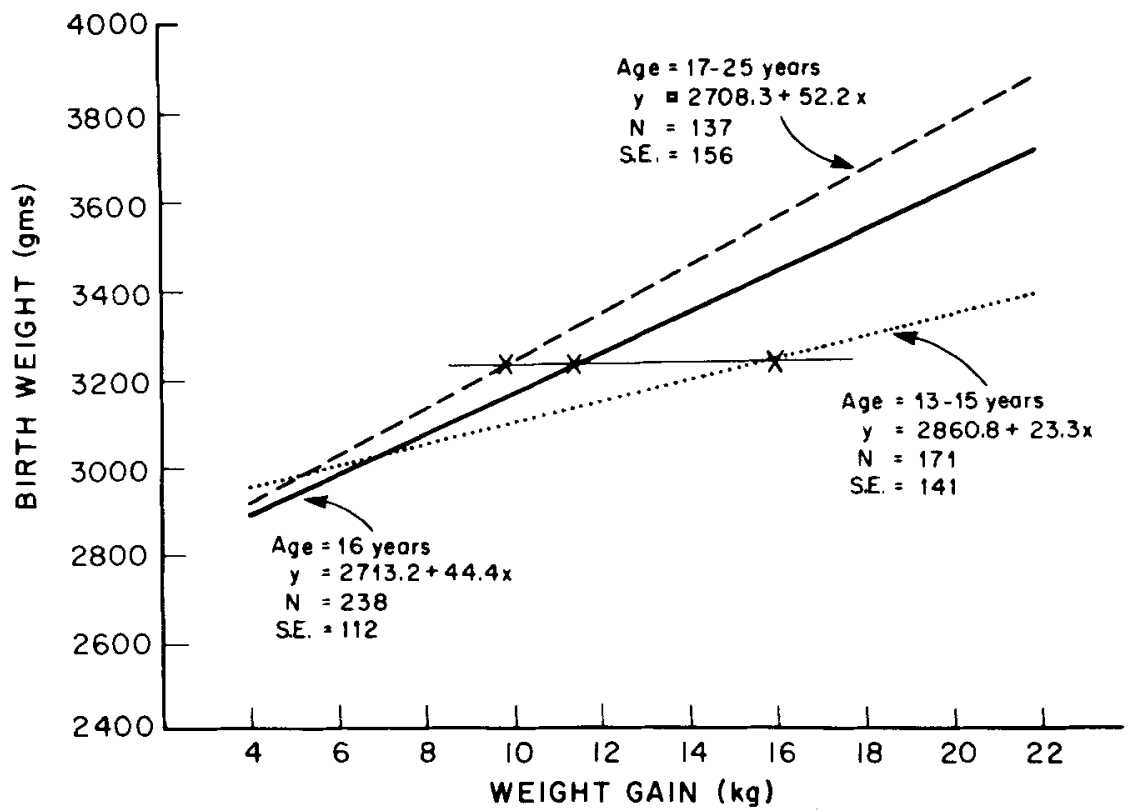

Fig. 2. Relationship of pregnancy weight gain to newborn weight. Note that young teenage mothers, even though they had the same pregnancy weight gain, had offspring which were smaller than those born to older women. 
TABLE 6. Comparison of birth weight, placenta weight, maturity scores, and gestational ages of infants born to gynecologically immature adolescent mothers (gynecological age less than 2 years) and gynecologically mature adolescent mothers (gynecological age greater than 2 years) adjusted for anthropometric indicators of nutritional status

\begin{tabular}{|c|c|c|c|c|c|c|c|}
\hline \multirow{2}{*}{$\begin{array}{l}\text { Newborn } \\
\text { variable }\end{array}$} & \multicolumn{3}{|c|}{ Low gynecological age } & \multicolumn{3}{|c|}{ High gynecological age } & \multirow{2}{*}{$\begin{array}{c}\text { F- } \\
\text { Test }\end{array}$} \\
\hline & $\mathbf{N}$ & Mean & S.E. & $\mathrm{N}$ & Mean & S.E. & \\
\hline \multicolumn{8}{|c|}{ Adjusted for pregnancy weight gain } \\
\hline Birth weight (gm) & 128 & 3087.4 & 31.5 & 240 & 3073.9 & 23.0 & N.S. \\
\hline Placenta weight (gm) & 115 & 543.1 & 8.5 & 229 & 546.2 & 6.0 & N.S. \\
\hline $\begin{array}{l}\text { Physical maturity } \\
\text { score }\end{array}$ & 119 & 19.4 & 0.2 & 216 & 19.3 & 0.2 & N.S. \\
\hline $\begin{array}{l}\text { Neuromuscular } \\
\text { maturity score }\end{array}$ & 121 & 19.3 & 0.2 & 216 & 19.3 & 0.1 & N.S. \\
\hline $\begin{array}{l}\text { Gestational age by } \\
\text { maturity score (wk) }\end{array}$ & 117 & 39.5 & 0.1 & 211 & 39.5 & 0.1 & N.S. \\
\hline $\begin{array}{l}\text { Gestational age by last } \\
\text { menstruation (wk) }\end{array}$ & 105 & 38.2 & 0.2 & 209 & 38.0 & 0.2 & N.S. \\
\hline \multicolumn{8}{|c|}{ Adjusted for height and weight at delivery } \\
\hline Birth weight (gm) & 127 & 3087.7 & 31.5 & 239 & 3071.7 & 22.9 & N.S. \\
\hline Placenta weight $(\mathrm{gm})$ & 114 & 543.4 & 8.5 & 228 & 546.6 & 6.0 & N.S. \\
\hline $\begin{array}{l}\text { Physical maturity } \\
\text { score }\end{array}$ & 118 & 19.4 & 0.2 & 215 & 19.3 & 0.2 & N.S. \\
\hline $\begin{array}{l}\text { Neuromuscular } \\
\text { maturity score }\end{array}$ & 120 & 19.3 & 0.2 & 216 & 19.3 & 0.1 & N.S. \\
\hline $\begin{array}{l}\text { Gestational age by } \\
\text { maturity score (wk) }\end{array}$ & 116 & 39.5 & 0.1 & 211 & 39.5 & 0.1 & N.S. \\
\hline $\begin{array}{l}\text { Gestational age by last } \\
\text { menstruation (wk) }\end{array}$ & 104 & 38.2 & 0.2 & 208 & 38.0 & 0.2 & N.S, \\
\hline \multicolumn{8}{|c|}{ Adjusted for sum of skinfolds at delivery } \\
\hline Birth weight $(\mathrm{gm})$ & 124 & 3077.3 & 33.6 & 256 & 3070.1 & 23.4 & N.S. \\
\hline Placenta weight (gm) & 111 & 547.9 & 8.9 & 244 & 543.3 & 6.0 & N.S. \\
\hline $\begin{array}{l}\text { Physical maturity } \\
\text { score }\end{array}$ & 112 & 19.5 & 0.2 & 224 & 19.2 & 0.2 & N.S. \\
\hline $\begin{array}{l}\text { Neuromuscular } \\
\text { maturity score }\end{array}$ & 114 & 19.4 & 0.2 & 223 & 19.3 & 0.1 & N.S. \\
\hline $\begin{array}{l}\text { Gestational age by } \\
\text { maturity score (wk) }\end{array}$ & 110 & 39.6 & 0.1 & 219 & 39.4 & 0.1 & N.S. \\
\hline $\begin{array}{l}\text { Gestational age by last } \\
\text { menstruation (wk) }\end{array}$ & 101 & 38.2 & 0.2 & 215 & 37.9 & 0.2 & N.S. \\
\hline
\end{tabular}

equaled their father's height, and on the average the teenager's height at delivery equalled only $92 \%$ of the father's height. For operational purposes and for lack of a better indicator of relative growth status, we used the following two approaches to classify the relative growth status of the teenagers. First, we classified those teenagers whose height was greater than their mothers' height and greater than $92 \%$ of their fathers' height as having completed their growth; those whom height was less than the mothers' height and less than $92 \%$ of the fathers' height were classified as still growing. Table 7 compares the birth weight of infants born to adolescent mothers who have either completed their growth or not completed their expected growth. These data show that those teenagers who, at the time of delivery, were shorter than their mothers or had attained less than $92 \%$ of their fathers' height had significantly smaller newborns than their counterparts who were both taller than their mothers and had attained more than $92 \%$ of their fathers' height.

Since the results are quite similar when using either the mothers' or fathers' height, and because there were more teenagers with information on mother's height than on father's height, a second classification was used in subsequent analyses, in which only comparison with the mother's height was used to assess relative growth status of the teenager.

\section{Multivariate analyses}

In order to determine the relative role of maternal age in variability of newborn weight, multiple regression and path analysis were used.

Multiple regression: The relationship of maternal characteristics to birth weight was evaluated using multiple regression equa- 
TABLE 7. Comparison of birth weight of infants born to adolescent mothers 13 to 15 years old who have either completed or not completed their expected growth in height

\begin{tabular}{|c|c|c|c|}
\hline \multirow[b]{2}{*}{ Adolescent's relative growth } & \multicolumn{3}{|c|}{ Newborn weight (gm) } \\
\hline & $\mathrm{N}$ & Mean & S.D. \\
\hline Height less than $100 \%$ of mother's height & 177 & 3012.3 & 370 \\
\hline $\begin{array}{l}\text { Height greater than } 100 \% \text { of mother's height } \\
\text { F-test }\end{array}$ & 247 & $\begin{array}{l}3108.2 \\
6.55^{*}\end{array}$ & 388 \\
\hline Height less than $92 \%$ of father's height & 90 & 2991.3 & 373 \\
\hline $\begin{array}{l}\text { Height greater than } 92 \% \text { of father's height } \\
\text { F-test }\end{array}$ & 136 & $\begin{array}{l}3098.9 \\
4.26 *\end{array}$ & 391 \\
\hline $\begin{array}{l}\text { Height less than } 100 \% \text { of mother's height } \\
\text { and less than } 92 \% \text { of father's height }\end{array}$ & 59 & 2944.3 & 370 \\
\hline $\begin{array}{l}\text { Height greater than } 100 \% \text { of mother's height } \\
\text { and greater than } 92 \% \text { of father's height }\end{array}$ & 102 & 3100.1 & 410 \\
\hline F-test & & $5.78^{*}$ & \\
\hline
\end{tabular}

${ }^{*} \mathrm{p}<0.05$.

tions in which maternal age, gynecological age, height, prepregnancy weight, pregnancy weight gain, weight at delivery, sum of skinfold thickness, maternal upper-arm muscle area, hemoglobin, hematocrit, serum albumin, serum protein, serum iron, and percent serum transferrin were controlled. Only those independent variables which were significant at the $\mathrm{p}<0.05$ level were included in the regression equations. Then, the slope (b) of each variable was evaluated separately for significant differences using analysis of covariance.

Using multiple and stepwise regression analysis, we quantified the relative contribution of the independent variables to birth weight. Table 8 presents the multiple regressions that best predict birth weight of infants born to still-growing adolescent mothers and to those who had completed their growth. In both cases, the best predictors of birth weight were pregnancy weight gain, gestational age, and placenta weight. Furthermore, the regression coefficient for pregnancy weight gain $\left(b_{1}\right)$ was higher in those who had completed their growth, relative to those who were still growing.

From what has been presented thus far, one might validly argue that the differences in weight between newborns of mothers who have completed growth and those who have not is merely a function of maternal height. To assess the contribution of maternal height to birth weight, the sample of teenage mothers was partitioned into a "tall" and a "short" group, those above and below the 50th percentile for their age. As shown in Table 9, the difference in mean birth weight between the children of tall and short mothers is the same as that between the children of mature and immature mothers (96 and 95
TABLE 8. Comparison of the regression equations that best predict the birth weight of infants born to young adolescent mothers (aged 13 to 15 years) who have either completed or not completed their expected growth in height

\begin{tabular}{lcr}
$\begin{array}{l}\text { Regression } \\
\text { equation }\end{array}$ & $\begin{array}{c}\text { Incomplete } \\
\text { growth }\end{array}$ & $\begin{array}{c}\text { Complete } \\
\text { growth }\end{array}$ \\
\hline Constant (a) & -2638.3 & -1801.7 \\
Pregnancy weight gain $\left(\mathrm{b}_{1}\right)$ & 52.6 & 72.7 \\
Gestation length $\left(\mathrm{b}_{2}\right)$ & 119.2 & 94.2 \\
Placenta weight $\left(\mathrm{b}_{3}\right)$ & 0.78 & 0.9 \\
S.E. $(\mathrm{gm})$ & 304.2 & 284.4 \\
N & 124 & 183 \\
\hline
\end{tabular}

gm, respectively). However, it is also clear from the result in Table 9 that the tall mothers are gaining, on average, 967 gm more than their shorter peers, while the mature mothers are gaining only an average of 449 gm more than the immature mothers. Hence, it appears that the taller mothers are gaining much more weight to produce equivalent increases in newborn weight.

The same result may be obtained by regressing birth weight versus maternal weight gain. As shown in Table 9, the difference in regression slopes between the mature and immature groups is larger than that between the tall and the short groups, indicating that per unit of maternal weight gain mature mothers produce larger babies than immature ones. Finally, if the mean birth weights are adjusted for maternal weight gain, we see that the differences between the newborns of tall and short mothers disappears, while a substantial difference remains between the children of mature and immature mothers. Therefore, it appears that height influences newborn weight because taller mothers are able to gain more weight than shorter ones; however, mature mothers 
TABLE 9. Comparison of the relationship between newborn weight and maternal pregnancy weight gain in tall vs. short mothers, and mature vs. immature mothers

\begin{tabular}{|c|c|c|c|c|c|c|c|}
\hline \multirow[b]{2}{*}{ Criterion } & \multirow[b]{2}{*}{$\mathrm{N}$} & \multicolumn{2}{|c|}{ Unadjusted means } & \multicolumn{2}{|c|}{$\begin{array}{l}\text { Newborn weight } \\
\text { vs.maternal } \\
\text { weight gain } \\
\text { regression }\end{array}$} & \multicolumn{2}{|c|}{$\begin{array}{l}\text { Newborn weight } \\
\text { adjusted for } \\
\text { maternal weight } \\
\text { gain }\end{array}$} \\
\hline & & $\begin{array}{c}\begin{array}{c}\text { Newborn } \\
\text { weight }\end{array} \\
\end{array}$ & $\begin{array}{c}\text { Maternal } \\
\text { weight gain }\end{array}$ & B & S.E. & Mean & $\mathbf{F}$ \\
\hline $\begin{array}{l}\text { Relative growth } \\
\text { Immature }\end{array}$ & 157 & 3012 & 9409 & 0.07 & 0.02 & 3035 & \multirow{2}{*}{$3.2^{*}$} \\
\hline $\begin{array}{l}\text { Mature } \\
\text { Height }\end{array}$ & 220 & 3108 & 9858 & 0.10 & 0.02 & 3103 & \\
\hline Short & 200 & 3020 & 9200 & 0.08 & 0.02 & 3049 & \multirow{2}{*}{1.3} \\
\hline Tall & 183 & 3115 & 10167 & 0.09 & 0.02 & 3095 & \\
\hline
\end{tabular}

${ }^{*} p<0.05$

TABLE 10. Path coefficients ( $\beta$ ) of the determinants of birth weight of infants born to young adolescent mothers (13 to 15 years) who have either completed or not completed their expected growth in height

\begin{tabular}{lcc}
\hline & $\begin{array}{c}\text { Incomplete } \\
\text { growth } \\
\mathrm{N}=139 \\
(\beta)\end{array}$ & $\begin{array}{c}\text { Complete } \\
\text { growth } \\
\mathrm{N}=190 \\
(\beta)\end{array}$ \\
\hline Weight gain & & \\
$\quad$ Direct & 0.203 & 0.306 \\
Indirect via placenta & 0.097 & 0.082 \\
Total effect & 0.300 & 0.388 \\
Gestational age & 0.579 & 0.453 \\
Direct & 0.034 & 0.126 \\
Indirect via placenta & 0.613 & 0.579 \\
Total effect & & \\
Placenta weight & 0.341 & 0.465 \\
Direct or total effect & & \\
\hline
\end{tabular}

are able to produce heavier babies with relatively lower weight gain, indicating that the difference between mature and immature mothers is not merely height but, rather, "energetic efficiency" as well.

Path analysis: To explore the interdependence and direct influence of the three best predictors (pregnancy weight gain, gestation length, and placenta weight) of birth weight, a path analysis was carried out. Following the protocol of $\mathrm{Li}$ (1981), all the variables were first standardized whereby each individual value is expressed as the difference between the age-specific mean divided by the standard deviation (i.e., if an individual value for birth weight is 2900 and the age-specific mean and standard deviation are $3200 \pm$ 400 , the corresponding standardized value would be 0.75 ). Thereafter, one-way causal models were tested by calculating path coefficients after performing consecutive and exclusive multiple regression analyses.
In Table 10 are summarized the direct and indirect influences of each variable on weight of infants born to young adolescent mothers who either completed or had not completed their growth. These influences are expressed as path coefficients. Since the placenta is the medium whereby the maternal factors influence prenatal growth (Gruenwald, 1975; Munro, 1980), the path assumes that the indirect effects of pregnancy weight gain and gestation length occur through their influence on the placenta, with the placenta in turn directly affecting the newborn weight. These data show that, as expected, the effects of pregnancy weight gain on birth weight are greater among the adolescents who completed their growth than in their counterparts that are still growing (this information was also evident from the original regression analysis). The net direct effect of an independent variable on birth weight can be calculated by multiplying the path coefficient by the standard deviation of birth weight $(\mathrm{Pi}$ cone et al., 1982). For example, for the adolescents who had not completed their expected growth, assuming the standard deviation of birth weight is $400 \mathrm{gm}$, an increase of $1.5 \mathrm{~kg}$ above the mean pregnancy weight gain of the group would result in an additional gain of only $81 \mathrm{gm}(0.203 \times 400)$ in birth weight. In contrast, among the adolescents who had completed their growth, an increase of $1.5 \mathrm{~kg}$ in pregnancy weight gain would cause an increase of $122 \mathrm{gm}(0.306 \times 400)$ in birth weight. Findings from path analysis that were not evident from the original regression analysis are as follows: (1) the contribution of gestation length to birth weight is similar in both groups of adolescents and (2) placenta weight exerts a strong indirect and direct 
effect on birth weight of newborns born to adolescents who had completed their growth, while placenta weight is less effective in modifying the birth weight of children born to still-growing adolescents.

\section{DISCUSSION}

From this study it is clear that young teenage mothers had smaller newborns than their older teenage and adult counterparts, even when birth weight was adjusted for maternal nutritional status. As the reduction in birth weight is not associated with lower gestational age, the low birth weight characteristic of teenage pregnancy cannot be explained on the basis of premature delivery or short gestation (Battaglia et al., 1963; Zlatnik and Burmeister, 1977). The data presented here show a persistently lower birth weight for offspring born to adolescent mothers whose nutritional status was similar to that of their older counterparts. These findings are similar to those found in a large sample of teenagers derived from the U.S. Collaborative Study (Naeye, 1981a; Garn et al., 1982). These analyses found that 10- to 16-year-old mothers had significantly smaller newborns than older mothers who were matched for pregnancy weight gain. In other words, in the U.S. as in the Peruvian sample, at the same level of nutritional status, young mothers have smaller newborns than older women.

We also found that the pregnancy weight gain associated with the average newborn weight is about $16 \mathrm{~kg}$ in the young mothers and 10 to $12 \mathrm{~kg}$ in older women. This difference can be explained by a growth and pregnancy factor. The natural increase in weight for nonpregnant poor urban females between the ages of 13 and 15 for a similar population is about 3 to $4 \mathrm{~kg}$ per year (Graham et al., 1979). Therefore, the total pregnancy weight gain of a 13- to 15-year-old adolescent should equal this expected growth gain plus the weight gain for pregnancy. Assuming the pregnancy weight gain associated with the average birth weight is the optimal weight gain, then the young teenager should gain at least $4 \mathrm{~kg}$ more than her older counterparts in order to produce the same size infant, which agrees quite closely with the present finding. In other words, the pregnancy weight gains that are optimal for prenatal growth should be higher in young teenagers than in older mothers because of the requirements of young teenagers for nutrients for their own as well as their fetuses' growth. Since skinfold thickness indicates the amount of calorie reserves (Frisancho et al., 1977a,b), the fact that at the same level of maternal nutritional status the young teenagers had newborns who were low in both weight and sum of skinfold thickness suggests that the availability of calories was less for the offspring of young teenagers than older women, despite their equal pregnancy weight gain. In other words, young mothers do not seem to enable their fetuses to accumulate as much calorie reserves as do the older women. Naeye (1981a) indicates that an acetonuria of $2+$ or greater was more than twice as frequent in 10- to 14-year-old mothers as in older mothers, which indicates an increased metabolization of adipose tissue among young pregnant teenagers.

Previous investigators have demonstrated that parity, maternal morbidity, fetal intrauterine infection, frequency of coitus during the last trimester, maternal smoking, maternal alcohol consumption, and socioeconomic factors are associated with reduction in birth weight (Naeye, 1981a,b; McAnarney et al., 1981). In the present study only primiparous subjects who did not smoke or use alcohol were included in the analyses, and these factors can safely be excluded. On the other hand, we do not have information on frequency of coitus and if there is a difference between the adolescent mothers and older mothers it is quite possible that this factor may play a role in the reduction of birth weight. However, an analysis of variance aimed at determining the effect of socioeconomic status on birth weight indicated that differences in the birth weight between the offspring of young adolescent and older adolescent mothers were more due to differences in nutritional status than socioeconomic status.

This study also indicates that gynecological age per se does not directly affect preg. nancy outcome. Previous studies on the effects of gynecological age on prenatal growth have been contradictory. Some studies indicate that a low gynecological age is associated with an increased prevalence of low birth weight and toxemia (Erkan et al., 1971; Zlatnik and Burmeister, 1977) while others find no association between gynecological age and neonatal outcome (Hollingsworth and Kotchen, 1981; Naeye, 1981a). The lack of relationship between gynecological age and pregnancy outcome may be related 
to the fact that age at menarche has an error component, and the error may vary with the population samples. In other words, gynecological maturity may not be reflected accurately in gynecological age. Therefore, it is quite possible that, with the use of a better measure of gynecological maturity, a relationship between physiological maturity and pregnancy outcome would emerge.

As inferred from both multiple regression and path analyses, the contribution of pregnancy weight gain toward newborn weight is less in the adolescents who are expected to continue growing than in their counterparts who have completed their growth. For example, among the adolescents who have completed growth, the ratio of newborn weight to pregnancy weight gain (newborn weight/ pregnancy weight gain $\times 100$ ) equals about 33.05 ; this value is $31.08 \%$ for adolescents who have not completed their growth.

At present, we do not know by what physiological mechanisms adolescent mothers who are still expected to grow have smaller newborns than their counterparts who have completed their growth. There are, however, several possible explanations.

First, the reduction in birth weight might be due to a competition for nutrients between the adolescent mother and her fetus. Previous investigations on twins, siblings, parent-offspring similarities in growth, and comparative population studies (Garn and Rohmann, 1966; Hunt, 1966; Johnston et al., 1976; Tanner, 1978; Frisancho et al., 1980) have demonstrated that the influence of genetic factors on growth in height is greater during adolescence than during childhood. Furthermore, adolescent growth is characterized by an extreme variability in the age of growth-spurt onset and height growth termination. Although about $95 \%$ of the mature height is attained by menarche, a great deal of variability occurs in the amount of growth afterwards. For example, the U.S. Fels longitudinal study showed that the increase in height after menarche of those in the 10th percentile of height for age was about $4.3 \mathrm{~cm}$. On the other hand, the increase in height of those in the 90th percentile for the same study was about $10.6 \mathrm{~cm}$ (Roche and Davila, 1972). In terms of nutritional requirements, one would expect from these data that a pregnant teenager who had not completed her growth would have higher nutritional needs than the young woman who had attained her mature height. Furthermore, in view of the prevalent influence of the genetic component during adolescence one would expect that pregnant teenagers who have not yet reached their adult statures would be actively growing. Thus, unless she had a higher nutritional intake, the pregnant teenager who had not completed her growth would end up com. peting for nutrients with her own fetus. Applying this concept to the present study and as illustrated in Figure 3, it is likely that the adolescents who were both physically (growth completed) and gynecologically (gynecological age $>2$ years) mature at the time of pregnancy would be spared the nutritionally taxing influence of pregnancy and so produce larger babies. On the other hand, those individuals who were both physically (growth not yet complete) and gynecologically (gynecological age $<2$ years) immature at the time of pregnancy would attempt to fulfill their genetic growth potential even at the expense of their own fetuses' growth, resulting in low birth weight.

Second, the reduction in birth weight might reflect an inability of the immature mother to deliver nutrients to the fetus. The path analysis illustrated in Figure 4 indicates that the contribution of the placenta weight to newborn weight is enhanced among the adolescents who have completed their growth as compared to those who are still growing. Since placenta size per se does not limit fetal growth, the greater contribution of placenta weight to newborn weight in the older adolescents indicates that the reduction in birth weight among immature adolescents is related to differences in placenta function rather than in placenta size per se. Because utero-placental blood flow is the main regulator of placental growth (Gruenwald, 1975; Munro, 1980), it is quite possible that among the adolescents who had not completed their expected growth the utero-placental blood flow was reduced. Although we do not know the actual mechanism, how this occurs can be inferred from animal experimental studies. In vitro studies of the placenta have dem. onstrated that while malnutrition does not interfere with the rate of alpha-amino isobutyric acid (AIB) uptake, it does reduce the rate of placental blood flow (Rosso, 1980). Furthermore, measurements of cardiac output and organ blood flow using radioactive microspheres in anesthetized control and food-restricted rats have demonstrated that malnourished mothers do not expand cardiac output and placental blood to the same ex- 


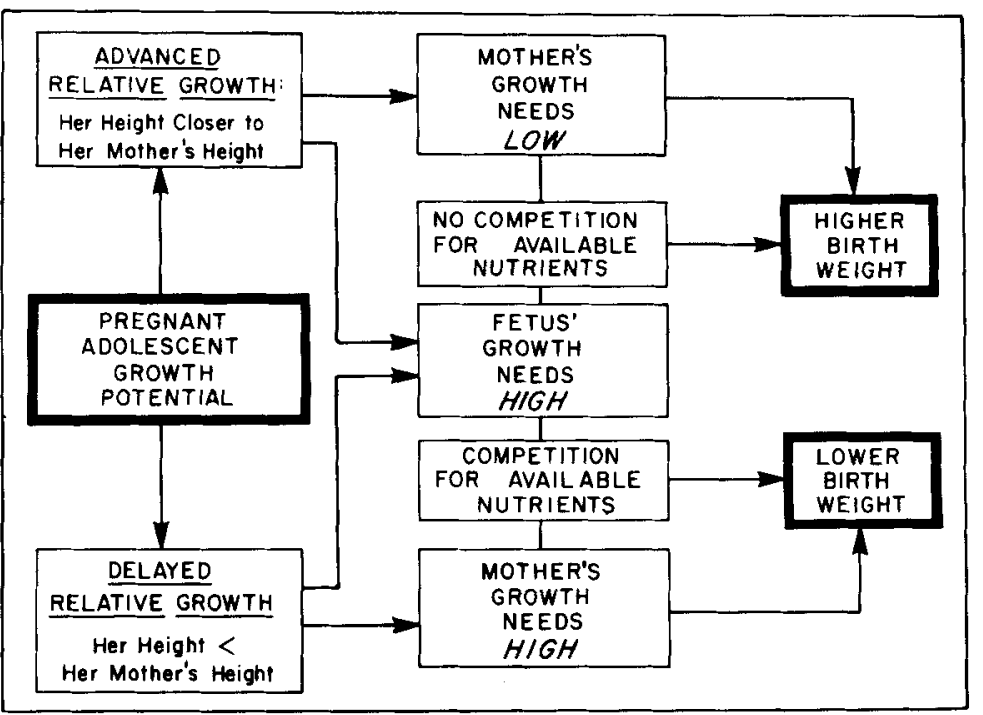

Fig. 3. Schematization of the interaction of adolescent growth status, physiological maturity, placenta function, and maternal and fetal growth needs.

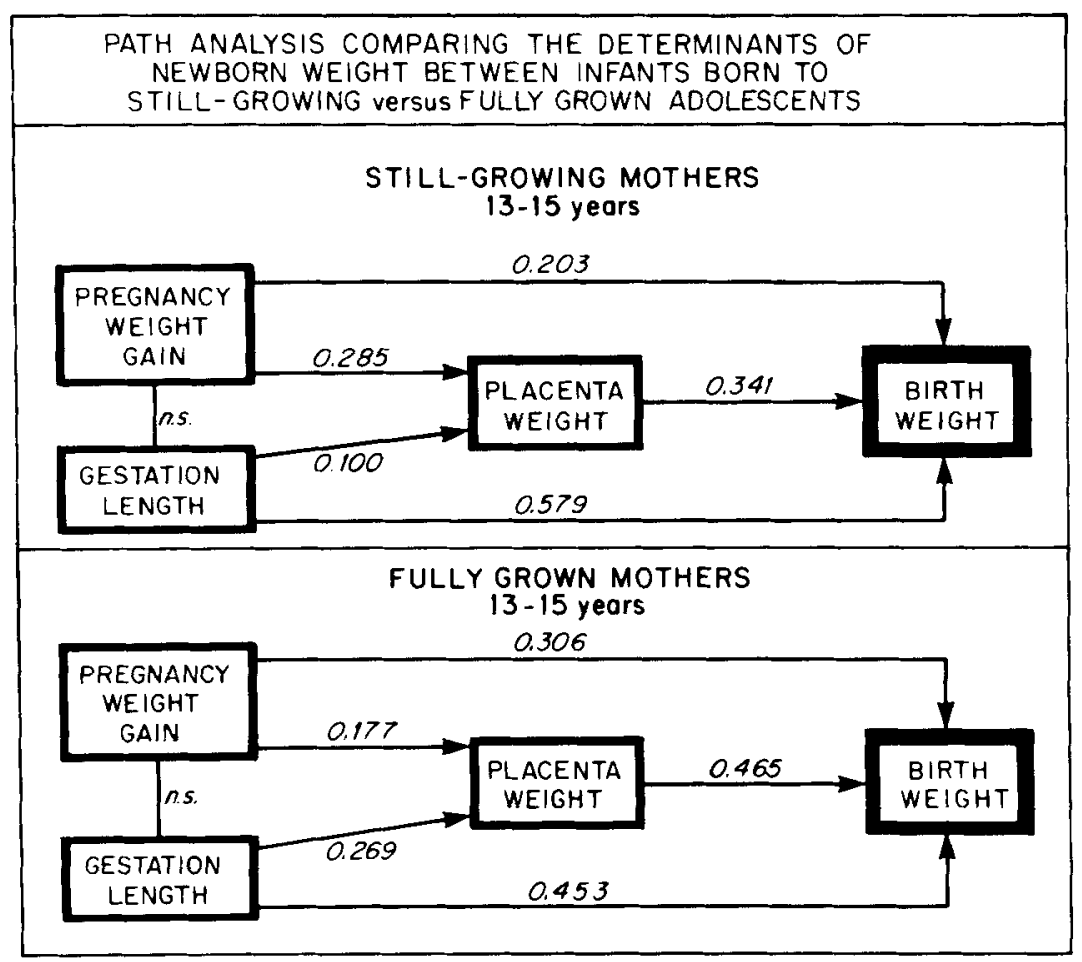

Fig. 4. Schematization of the determinants of newborn weight among infants born to stillgrowing and fully grown teenagers. Note that the contribution of the placenta to birth weight is much greater among the teenagers who have completed their growth. 
tent as well-fed mothers (Kava and Rosso, 1979). Applying these findings to the present study would imply that the fetal growth-retarding effects of the maternal-fetal competition for nutrients in the immature stillgrowing adolescent occur through a deficiency of placenta function. These findings together would suggest that the reduction in birth weight among immature still-growing adolescents may result from both a decreased net availability of nutrients and a deficient placental function that causes a reduction of fetal growth.

\section{CONCLUSIONS}

From this extensive study it is evident that young teenagers have smaller newborns than adult women. This difference occurs even when the young teenagers and adult women are matched for nutritional status. These findings also indicate that maternal gynecological age per se does not affect prenatal growth. As inferred from multivariate analyses, it appears that the reduction in birth weight among young teenagers can be explained in part by a decreased net availability of nutrients resulting from the competition for nutrients between the mother's growth needs and those of her fetus and by the inability of the teenage placenta to function adequately, which results in a retarded fetal growth.

The individual and mean birth weights (3150 gm) of the present sample are quite similar to those reported for U.S. white 13 . to 15-year-old teenagers, and higher than those reported for black teenagers of the same age range (Naeye, 1981a). However, because U.S. teenagers do not grow during pregnancy (Garn et al., 1982), and because their infants' low birth weights are more a function of prematurity than prenatal growth retardation, these findings cannot be applied to all populations.

\section{ACKNOWLEDGMENTS}

This study was supported in part by Grant BNS 79-24735 of the National Science Foundation and by research funds from the University of Michigan. The authors thank the mothers who participated in this study and the staff of the Maternity Hospital of Lima, Peru, without whom this study would not have been possible.

\section{LITERATURE CITED}

Ballard, JL, Novak, KK, and Driver, M (1979) A simplified score for assessment of fetal maturation of newly born infants. J. Pediatr. 95:769-774.
Battaglia, FG, Frazier, TM, and Hellegers, AE (1963) Obstetric and pediatric complications of juvenile pregnancy. Pediatrics 39:902

Briggs, RM, Herren, RR, and Thompson, WB (1962) Pregnancy in the young adolescent. Am. J. Obstet. Gynecol. 84:436-441.

Claman, AD, and Bell, HM (1964) Pregnancy in the very young teenager. Am. J. Obstet. Gynecol. 90:350.

Clark, JF (1971) Adolescent obstetrics, obstetric and sociologic implications. Clin. Obstet. Gynecol. 14:1026.

Coates, JB (1970) Obstetrics in the very young adolescent. Am. J. Obstet. Gynecol. 108:68.

Coetzee, LF (1970) Pregnancy in the South African nonwhite teenager. S. Afr. Med. J. 44:1373.

Duenhoelter, JH, Jiminez, JM, and Bauman, G (1975) Pregnancy performance of patients under fifteen years of age. Obstet. Gynecol. 46:49.

Erkan, KA, Rimer, BA, and Stine, OC (1971) Juvenile pregnancy-role of physiologic maturity. Md. State Med. J. 20:50.

Frisancho, AR, Klayman, JE, and Matos, J (1977a) Influence of maternal nutritional status on prenatal growth in a Peruvian urban population. Am. J. Phys. Anthropol. 46:265-274.

Frisancho, AR, Klayman, JE, and Matos, J (1977b) New born body composition and its relationship to linear growth. Am. J. Clin. Nutr. 30:704-711.

Frisancho, AR, Guire, K, Babler, W, Borkan, B, and Way, A (1980) Nutritional influence on childhood development and genetic control of adolescent growth of Quechuas and Mestizos from the Peruvian lowlands. Am. J. Phys. Anthropol. 52:367-375.

Frisancho, AR (1981) New norms of upper limb fat and muscle areas for assessment of nutritional status. Am. J. Clin. Nutr. 34:2540-2545.

Frisancho, AR, Matos, J, and Flegel, P (1983) Maternal nutritional status and adolescent pregnancy outcome. Am. J. Clin. Nutr. 38:739-746.

Frisancho, AR, Matos, J, and Bollettino, LA (1984a) Influence of nutritional status and placenta function on birth weight of infants born to young still-growing teenagers. Am. J. Clin. Nutr. 40:801-807.

Frisancho, AR, Matos, J, and Bollettino, LA (1984b) Role of gynecological age and growth maturity status in fetal maturation and prenatal growth of infants born to young still-growing adolescent mothers. Hum. Biol. 56:583-593.

Garn, SM, and Rohmann, CG (1966) Interaction of nutrition and genetics in the timing of growth and development. Pediatr. Clin. North Am. 13:353-379.

Garn, SM, Pesik, SD, and Petzold, AS (1982) The biology of teen-age pregnancy; the mother and the child. Presented at conference on school-age pregnancies and parenthood. Elkridge, MD: Social Sciences Research Council.

Graham, GG, MacLean, Jr., WC, Kallman, CH, Rabold, J, and Mellits, ED (1979) Growth standards for poor urban children in nutrition studies. Am. J. Clin. Nutr. 32:703.

Gruenwald, P (1975) The supply line of the fetus: Definitions relating to fetal growth. In $\mathrm{P}$ Gruenwald (ed): The Placenta and Its Maternal Supply Line. London: Butterworths, pp. 1-17.

Gueri, M, Jutsum, P, and Sorhaindo, B (1982) Anthropometric assessment of nutritional status in pregnant women: A reference table of weight-for-height by week of pregnancy. Am. J. Clin. Nutr. 35:609-611.

Hollingsworth, DR, and Kotchen, JM (1981) Gynecological age and its relation to neonatal outcome. Birth Defects XVII (3):91-105.

Hulka, J, and Schaaf, JT (1964) Obstetrics in adoles- 
cents: A controlled study of deliveries by mothers 15 years of age or younger. Obstet. Gynecol. 23:678.

Hunt, EE (1966) The developmental genetics of man. In F Faulkner (ed): Human Development. Philadelphia: WB Saunders.

Israel, SL, and Wouterz, TB (1963) Teenage obstetrics. AM. J. Obstet. Gynecol. 85:649.

Johnston, RE, Wainer, $H$, Thissen, $D$, and MacVean, $R$ (1976) Hereditary and environmental determinants of growth in height in a longitudinal sample of children and youth of Guatemalan and European ancestry. Am. J. Phys. Anthropol. 44:469-476.

Kava, R, and Rosso, P (1979) Mechanisms for fetal growth retardation in undernourished pregnant rats. Fed. Proc. 38:871 (abstr).

Li, CC (1981) Path Analysis: A Primer. Pacific Grove, CA: The Boxwood Press.

McAnarney, ER, Stickle, G, Paul, NW, and Greene, SC (eds) (1981) Pregnancy and childrearing during adolescence: Research priorities for the 1980 's. Birth Defects $X V I I(3)$

Munro, HN (1980) Placenta in relation to nutrition. Fed. Proc. 39:236-238.

Naeye, RL (1981a) Teenaged and pre-teenaged pregnancies: Consequences of the fetal-maternal competition for nutrients. Pediatries 67:146-150.

Naeye, RL (1981b) Coitus and antepartum haemorrhage. Br. J. Obstet. Gynaecol. 88:765-770.
Niswander, KR, and Gordon, M (1972) The Women and Their Pregnancies. Philadelphia, PA: W.B. Saunders Company.

Picone, TA, Allen, OH, Olsen, PN, and Ferris, ME (1982) Pregnancy outcome in North American women. II. Ef fects of diet, cigarette smoking, stress, and weight gain on placentas, and on neonatal physical and behavioral characteristics. Am. J. Clin. Nutr. 36:1214-1224.

Raugh, JL, Johnson, LB, and Burket, RL (1973) The reproductive adolescent. Pediatr. Clin. North Am. 20:1005.

Roche, AR, and Davila, GH (1972) Late adolescent growth in stature. Pediatries 50:874-880.

Rosso, P (1980) Placental growth, development, and function in relation to maternal nutrition. Fed. Proc. $39: 250-254$.

Stearn, RH (1963) The adolescent primigravida. Lancet 2:1083-1085.

Taffell, S (1980) Factors associated with low birth weight: United States, 1976. Hyattsville, MD: National Center for Health Statistics. DHEW Publication Number (PHS) 80-1915.

Tanner, JM (1978) Fetus Into Man. Cambridge, MA: Harvard University Press.

Zlatnik, FJ, and Burmeister, LF (1977) Low "gynecological age": An obstetric risk factor. Am. J. Obstet. Gy. necol. 128:183-186. 